\title{
Optical Properties of RF Sputtered Samarium Oxide Thin Films
}

\author{
M. M. Abd El-Raheem ${ }^{1,2 *}$, M. H. El Bogami², Ateyyah M. Al-Baradi², S. A. Amin ${ }^{3}$, \\ A. M. El-Naggar ${ }^{4,5}$, A. A. Albassam 4 \\ ${ }^{1}$ Department of Physics, Faculty of Sciences, Sohag University, Sohag, Egypt \\ ${ }^{2}$ Department of Physics, Faculty of Sciences, Taif University, Taif, KSA \\ ${ }^{3}$ Department of Physics, Faculty of Sciences, Assiut University, Assiut, Egypt \\ ${ }^{4}$ Exploitation of Renewable Energy Applications in Saudi Arabia, Physics \& Astronomy Department, College of \\ Science, King Saud University, Riyadh, Saudi Arabi \\ ${ }^{5}$ Physics Department, Faculty of Science, Ain Shams University, Cairo, Egypt \\ Email: "elneh@yahoo.com
}

Received 7 November 2015; accepted 22 November 2015; published 27 November 2015

Copyright (C) 2015 by authors and OALib.

This work is licensed under the Creative Commons Attribution International License (CC BY).

http://creativecommons.org/licenses/by/4.0/

(c) (i) Open Access

\section{Abstract}

This paper reports the optical properties of prepared samarium oxide $\mathrm{Sm}_{2} \mathrm{O}_{3}$ thin films nanoparticles using RF sputtering technique. $\mathrm{X}$-ray diffraction is used to examine and characterize the prepared films. Optical measurements are carried out by employing U-V-Visible spectroscopy to study optoelectronic properties of $\mathrm{Sm}_{2} \mathrm{O}_{3}$ thin films. These films are highly transparent in the visible range. The average value of the optical gap belonging to the thin films deposited under different pressure of the gas is $4.33 \mathrm{eV}$. The refractive index (n) behaves as normal dispersion and decreases with increasing the pressure of the gas. The dispersion energy and single oscillator energy increase with increasing the pressure of the gas whereas the optical conductivity decreases with increasing the power on Sb target.

\section{Keywords}

Samarium Oxide, RF Sputtering, Optical Gap, Refractive Index, Dispersion Energy

Subject Areas: Experimental Physics

\section{Introduction}

High-dielectric constant $(\mathrm{k})$ materials have excessively been investigated to replace the conventional $\mathrm{SiO}_{2}$-based

"Corresponding author.

How to cite this paper: Abd El-Raheem, M.M., El Bogami, M.H., Al-Baradi, A.M., Amin, S.A., El-Naggar, A.M. and Albassam, A.A. (2015) Optical Properties of RF Sputtered Samarium Oxide Thin Films. Open Access Library Journal, 2: e2065. 
gate dielectric [1]-[4]. For industry it is necessary to obtain greater integrated circuit functionality and performance at lower cost. The circuit density must be increased, i.e. higher density of transistors on a wafer. On the other side, this shrinking of the transistor feature size has forced the channel length and gate dielectric thickness to decrease rapidly [5] The dielectric's thickness in integrated circuits has been decreased to $1-3 \mathrm{~nm}$ in order to achieve smaller physical dimensions, lower driving voltage and higher operation speed. The reduction in the oxide thickness would impose several problems, including a high level of the leakage current and a large degree of dopant (boron) diffusion in the gate oxide [6] [7]. This downscale of dimension will result in the replacement of $\mathrm{SiO}_{2}$ by other materials, due also to the excessive tunneling current and reliability issues. In sub-100 nm metal oxide semiconductors MOS devices, thickness of $\mathrm{SiO}_{2}$ should be reduced to less than $1.5 \mathrm{~nm}$ [8]. Shrinkage of the thickness below $1.5 \mathrm{~nm}$ resulted indirect tunneling of charges through the gate and led to large leakage current [3] [6]. Many candidates such as $\mathrm{TiO}_{2}$ and $\mathrm{HfO}_{2}$ [9]-[14] had been investigated as alternative dielectric materials to substitute $\mathrm{SiO}_{2}$. Rare-earth oxides had been identified and emerged as promising gate dielectric candidates for future MOS-device applications [15]-[26]. Samarium oxide $\mathrm{Sm}_{2} \mathrm{O}_{3}$ is a potential candidate to achieve comparable dielectric properties as those of $\mathrm{La}_{2} \mathrm{O}_{3}$ due to its large band gap (4.33 eV) and low leakage current density [27]-[30]. $\mathrm{Sm}_{2} \mathrm{O}_{3}$ thin film was deposited on $\mathrm{Si}$ substrate by various techniques such as physical vapor deposition (PVD) and RF magnetron sputtering [30]. Wen Chiao Chin et al. [31] found that $\mathrm{Sm}_{2} \mathrm{O}_{3}$ thin film had a huge potential to be the alternative dielectric for future MOS based devices. The effects of increase in sputtering power and substrate temperature on the microstructural, morphological and electrical characteristics of $\mathrm{Sm}_{2} \mathrm{O}_{3}$ thin films have been reported [32]. They observed that the crystallization of the films was increased with increase in sputtering power up to $200 \mathrm{~W}$ and decreased at the power of $250 \mathrm{~W}$. In addition, composition of the films was improved by both sputtering power and increase in substrate temperature. The grain boundaries and surface roughness of the films were also found to be significantly affected by the change in substrate temperature. Samarium oxide thin films were deposited on glass substrate by using spin coating technique, the XRD patterns of deposited thin films exhibited an amorphous nature at low temperature and transferred to the polycrystalline stated at above $550^{\circ} \mathrm{C}$ [33]. Hexagonal phase $\mathrm{Sm}(\mathrm{OH})_{3}$ nanoroll sticks were first synthesized by hydrothermal method, and cubic phase $\mathrm{Sm}_{2} \mathrm{O}_{3}$ nanoroll sticks were obtained by post-annealing treatment at $450^{\circ} \mathrm{C}$ [34].

As far as the authors know little attention has been paid to study the optical properties of sputtered $\mathrm{Sm}_{2} \mathrm{O}_{3}$ thin films under different conditions of preparation, therefore this paper focused in this point.

\section{Experimental Method}

Samarium oxide thin films in this study were deposited on pre-cleaned glass substrates using UNIVEX 350 SPUTTERING UNIT with RF power MODEL Turbo drive TD20classic (Leybold) and thickness monitor model INFICON AQM 160. The ceramic $\mathrm{Sm}_{2} \mathrm{O}_{3}$ target, from Cathey Advanced Materials Limited Company was used as a sputtering source. The sputtering chamber was evacuated to a base pressure of $2 \times 10^{-6}$ torr and then back filled with mixture of $98 \%$ pure argon $+2 \%$ pure $\mathrm{O}_{2}$ and up to the sputtering pressure of $2 \times 10^{-2}$ mbar and the sputtering pressure was maintained constant throughout the coating. Prior to deposition the substrates were cleaned using a $10 \%$ by volume solution of hydrofluoric acid followed by a rinse in deionizer water. The target substrate distance was $10 \mathrm{~cm}$ with an angle $65^{\circ}$. The standard cubic centimeter per minute $(\mathrm{sccm})$ maintained at value of $20 \mathrm{~cm}^{3} / \mathrm{min}$ with substrate rotation $2 \mathrm{rpm}$ and desired power depending on the condition of preparation. The rate of deposition was $2 \mathrm{~nm} / \mathrm{min}$. Film thicknesses were determined accurately after deposition by using multiple-beam Fizeau fringes in reflection, Tolansky method [35]. X-ray diffraction (XRD) patterns were recorded using Philips X-ray diffractometer model X' Pert with Cu Ka $\left(1.5406 \mathrm{~A}^{\circ}\right)$ radiation operated at $40 \mathrm{kV}$ and $25 \mathrm{~mA}$. The diffraction patterns were recorded automatically with scanning speed of $2 \mathrm{deg} / \mathrm{min}$.

Transmittance, $T(\lambda)$, and reflectance, $R(\lambda)$, of the as-deposited films were measured at normal incidence in the wavelength range $250-1200 \mathrm{~nm}$ by means of a double beam spectrophotometer (JASCO model V-670 UV-VisNIR) attached with constant angle specular reflection attachment $\left(5^{\circ}\right)$, to determine the spectral behavior of the optical constants and to deduce some optical parameters of $\mathrm{Sm}_{2} \mathrm{O}_{3}$ thin film. The spectral data obtained directly from the spectrophotometer were transformed to absolute values by making a correction to eliminate the absorbance and reflectance of the substrate. The absolute values of $T$ and Rare given by M. M. El-Nahass [36]

$$
T=\left(\frac{I_{f l}}{I_{g}}\right)\left(1-R_{g}\right)
$$


where $I_{f t}$ and $I_{g}$ are the intensities of the light passing through the film-glass system and that passing through the reference glass, respectively and $R_{g}$ is the reflectance of the glass substrate, and

$$
R=\left(\frac{I_{f r}}{I_{m}}\right) R_{m}\left(1+\left[1-R_{g}\right]^{2}\right)-T^{2} R_{g}
$$

where $I_{m}$ is the intensity of light reflected from the reference mirror, $I_{f r}$ is the intensity of light reflected from the film and $R_{m}$ is the mirror reflectance.

In order to estimate the optical energy gap in the absorption region of the spectra, it is better to calculate the absorption coefficient $\alpha$, and the absorption index, $k$, of the films at different wavelengths, therefore, the following equations are used [37]-[39]:

$$
\begin{gathered}
\alpha=\frac{1}{d} \operatorname{Ln}\left[\frac{(1-R)^{2}}{2 T}+\sqrt{\frac{(1-R)^{4}}{4 T^{2}}+R^{2}}\right] \\
k=\frac{\alpha \lambda}{4 \pi}
\end{gathered}
$$

where $\alpha$ is the absorption coefficient and $\mathrm{d}$ is the film thickness. The experimental error in measuring the film thickness was taken as $\pm 2 \%$, in $T$ and $R$ as $\pm 1 \%$ respectively.

\section{Results and Discussions}

X-ray diffraction patterns of as-prepared thin films show $\mathrm{SmO}_{2}$ peak at $2 \theta=40.6^{\circ}$ representing the plane (403) for the three films deposited under Ar pressure 20, 40, and 60 psi. Second peak of SmO is detected at $37.5^{\circ}$. The second peak at $37.5^{\circ}$ and preferred (111) plane is reported to by Jun-Gill Kang et al. [35] Lower peak is detected which indicates silicon preferred orientation plane (200) at $2 \theta=38.5^{\circ}$ as shown in Figure 1. The mean crystallite size $D$ of the film under test is estimated by using Scherrer equation [40]:

$$
D=\frac{K \lambda}{\beta \cos \theta}
$$

where $\lambda$ is the $\mathrm{X}$-ray wavelength of $\mathrm{CuK} \alpha(0.15418 \mathrm{~nm}), \beta$ is the width of the peak at half maximum intensity, and $\theta$ is the corresponding Bragg angle. The constant $K$ is of the order of 0.95 .

It is found that the crystallite size decreases from $36 \mathrm{~nm}$ to $23 \mathrm{~nm}$ with increasing the pressure of the gas from 20 to $60 \mathrm{psi}$ for the peak at $2 \theta=40.6^{\circ}$, besides it decreases from $24 \mathrm{~nm}$ to $17 \mathrm{~nm}$ with increasing the pressure from 20 to 60 psi for the second peak.

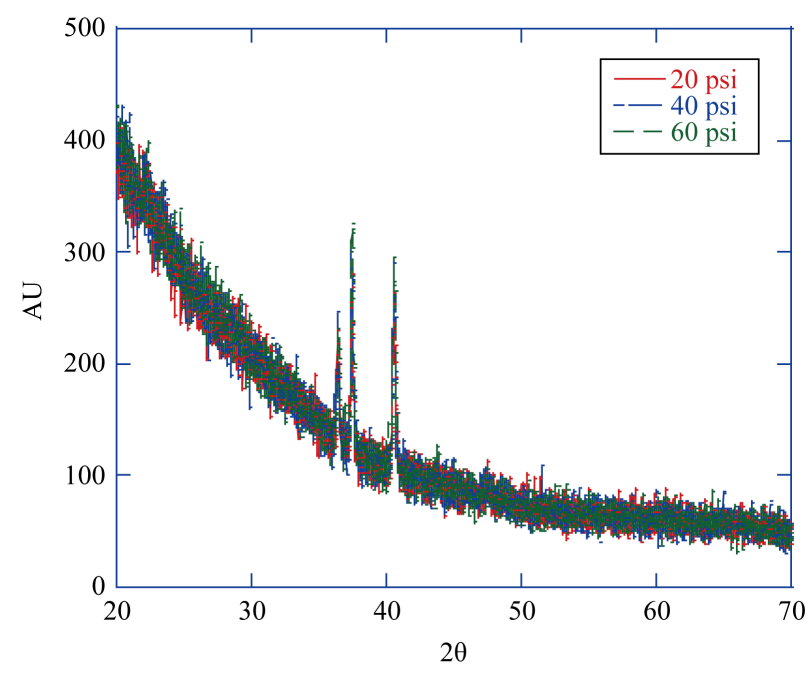

Figure 1. X-ray diffraction patterns for $\mathrm{Sm}_{2} \mathrm{O}_{3}$ thin films prepared under different pressure of the gas. 
Figure 2 displays the transmittance and reflectance spectra of $\mathrm{Sm}_{2} \mathrm{O}_{3}$ thin films in the wavelength range of $200-1200 \mathrm{~nm}$ deposited at under the same condition except different pressure of the gases 20, 40, and $60 \mathrm{psi}$. The spectra can be divided into two regions: In the wavelength range $260-320 \mathrm{~nm}$ the total sum of $\mathrm{T}$ and $\mathrm{R}$ is less than unity (absorption region), on the other side, at longer wavelength, the films become transparent and no light was absorbed, $T+R \approx 1$, (transparent region). The absorption edge is shifted to the longer wavelength side (red shift). This is attributed that, the 4f-5d electronic transitions had occurred in the $\mathrm{Sm}^{+2}$ ions. Some of $\mathrm{Sm}^{+2}$ ions were converted into $\mathrm{Sm}^{+3}$ ions. This explains the observed increase in the UV region. The optical transmittance spectra show that the $\mathrm{Sm}_{2} \mathrm{O}_{3}$ thin films are highly transparent in nature as its transparency is about 95\%.

To get information about direct or indirect inter-band transitions, the optical band gap was determined from the analysis of the spectral dependence of the absorption near the fundamental absorption edges within the framework of one electron theory [41]. The energy dependences of the interband absorption coefficient are given by the following expression, for allowed direct transitions [42],

$$
(\alpha h \vartheta)=A\left(h \vartheta-E_{g}\right)^{1 / 2}
$$

In the above equation, $E_{g}$ represents the optical band gap energy and $A$ is the characteristic parameter, independent on photon energy, for direct transition. The $(\alpha h \vartheta)^{2}$ vs $(h \vartheta)$ plot for the deposited films is shown in Figure 3. The direct band gap for the as-deposited films is evaluated from the $\mathrm{x}$-axis intercepts at $(\alpha h \vartheta)^{2}=0$. It was found that $E_{g}$ seem to be dependent on pressure of the gas where it has the values 4.395, 4.392, and 4.315 $\mathrm{eV}$ for the gas pressure 20, 40 and 60 psi respectively. The average value of the obtained $E_{g}$ is in consistent with the reported one $4.33 \mathrm{eV}$ [27] [43]. The decrease of the band gap is known to be associated with various many-body interactions between the carriers in the conduction band and valence band called band-gap normalization [44]. This operates simultaneously with Moss-Burstien band gap effect and reduces the magnitude of the optical band gap. The narrowing of the optical band gap may be due to removal of defect levels from the films [45]. On the other hand, the decrease in the optical band gap is basically due to the increase in the energy width of the band tails of localized states [46]. It is noted that the oxygen vacancies are known as color centers. The formation of color centers has been associated with an increase in electrical conductivity, in which free electrons are produced as a result of band-to-band transitions and trapping of these electrons in oxygen ion vacancies [47].

Figure 4 displays the spectral behavior of the absorption coefficient $\alpha$ showing a slight increase in the intensity of $\alpha$ with a red shift in the absorption edge by increasing the gas pressure. An absorption tail can be practically observed in the absorption coefficient which is a feature of most optical data for amorphous and polycrystalline semiconductors [48].

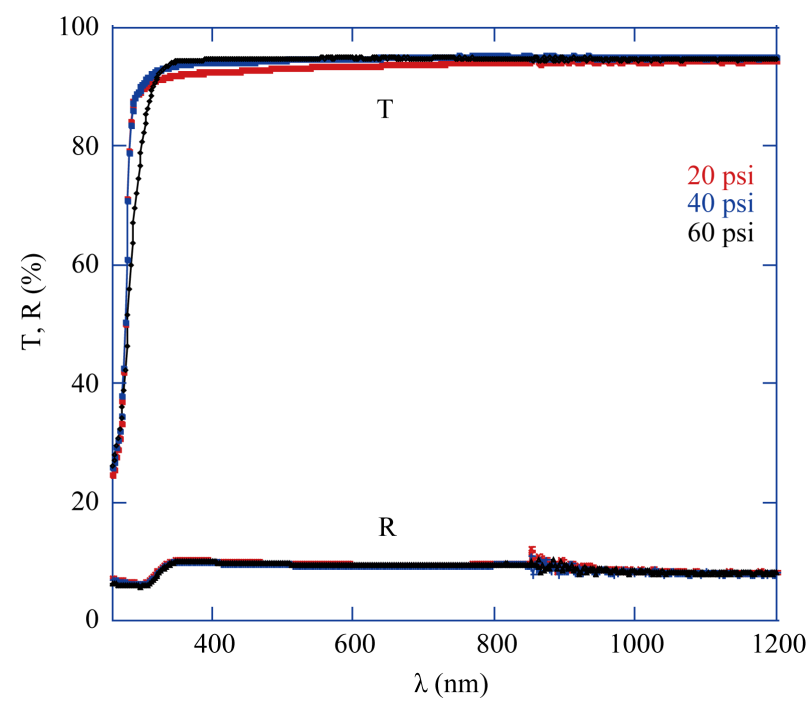

Figure 2. Transmittance and reflectance spectra for $\mathrm{Sm}_{2} \mathrm{O}_{3}$ thin films deposited under different pressure of argon oxygen mixture gas. 


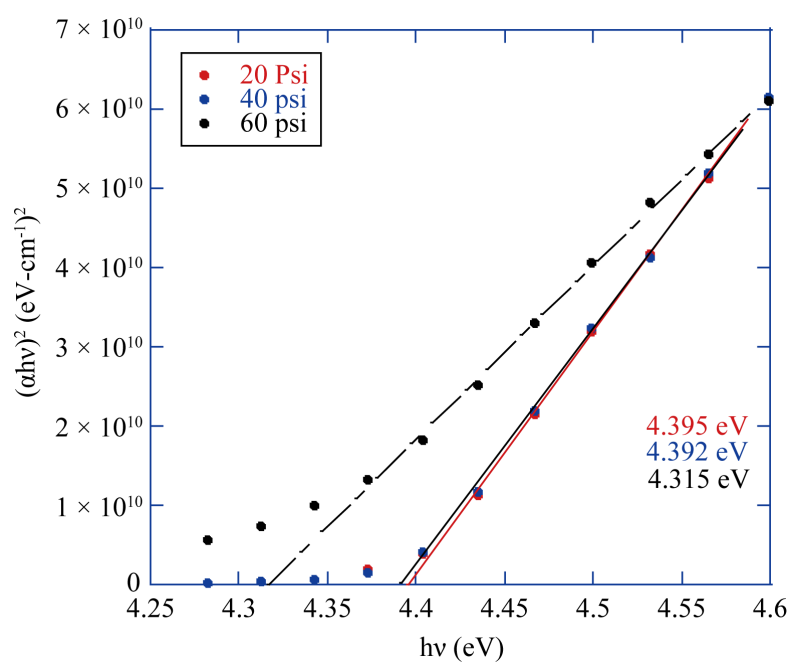

Figure 3. Plots of $(\alpha h v)^{2}$ versus incident photon energy for $\mathrm{Sm}_{2} \mathrm{O}_{3}$ thin films deposited under different pressure of argon gas.

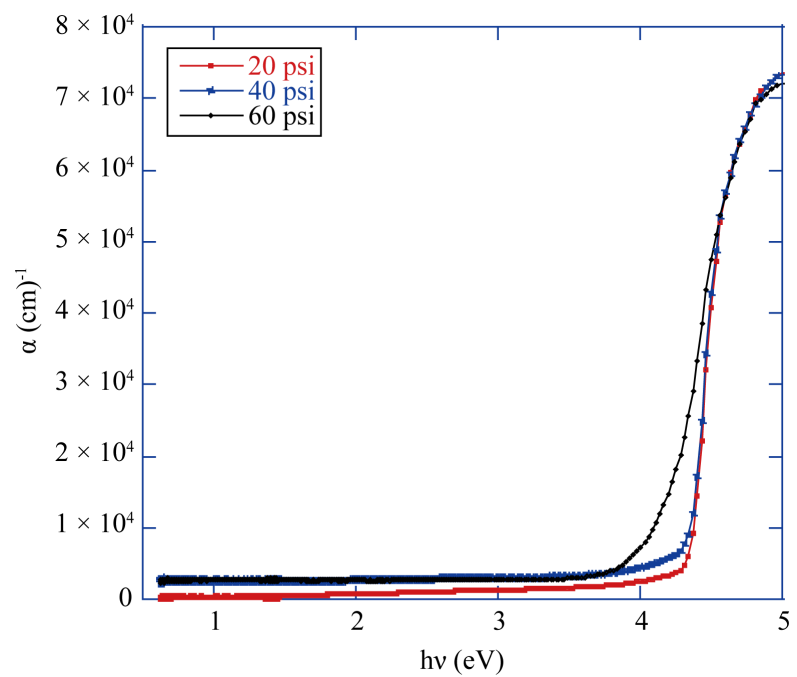

Figure 4. Spectral behavior of absorption coefficient $\alpha$ for $\mathrm{Sm}_{2} \mathrm{O}_{3}$ thin films deposited under different pressure of the gas.

Some tail states lie in the gap region which arise due to the presence of defects in the material. Therefore, the absorption of photons occurs even at energies lower than $E_{g}$. The absorption tail can be determined mainly due to structural disorder existing at the grain boundaries [48]. In this region the absorption coefficient $\alpha$ is said to obey Urbach role [49] [50].

$$
\alpha=\alpha_{o} \exp \left(\frac{h \vartheta}{E_{d}}\right)
$$

where $\alpha_{o}$ is a constant characterizes the materials and $E_{d}$ is the Urbach energy refers to the width of the tail states. Figure 5 displays the plots of $\operatorname{Ln}(\alpha)$ versus $h \vartheta$ for the as-deposited the fils under test. The values of $E_{d}$ can be obtained from the reciprocal of the slope of the straight line. The estimated values of $E_{d}$ are found to increase from $93 \mathrm{meV}$ to $219 \mathrm{meV}$ as the gas pressure increases from 20 psi to 60 psi respectively.

Figure 6 shows the real part of the refractive index, $n$, for as-deposited $\mathrm{Sm}_{2} \mathrm{O}_{3}$ thin films. It is observed that the refractive index is strongly dispersive in the wavelength range $330 \mathrm{~nm}<\lambda<360 \mathrm{~nm}$ (anomalous dispersion), 


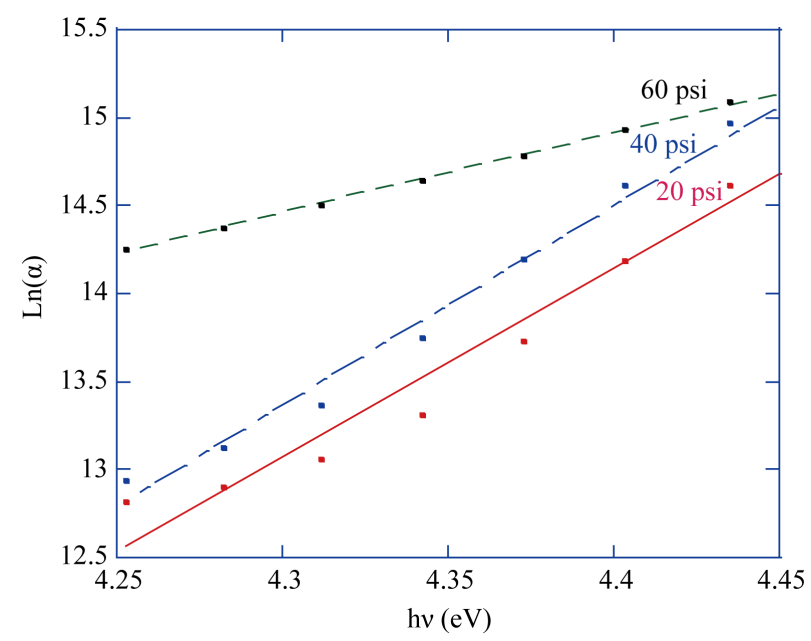

Figure 5. Plots of $\mathrm{Ln}(\alpha)$ versus $(h v)$ for $\mathrm{Sm}_{2} \mathrm{O}_{3}$ thin films prepared under different pressure of the gas.

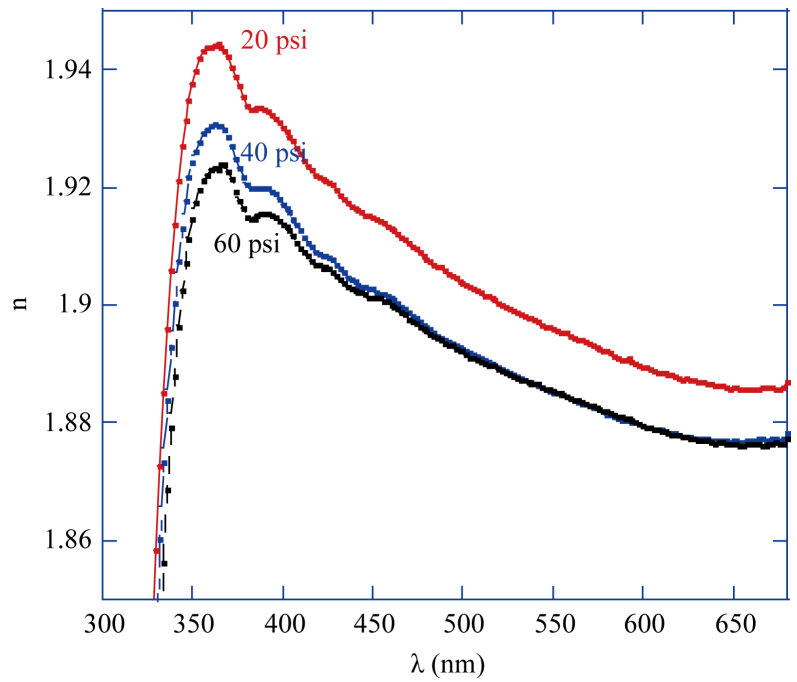

Figure 6. Refractive index (n) spectra for $\mathrm{Sm}_{2} \mathrm{O}_{3}$ thin films deposited under different pressure of the gas.

but changes slowly over the wavelength range $\lambda>360 \mathrm{~nm}$ (normal dispersion). At longer wavelength, the calculated value of the refractive index decreases with increasing the pressure of the gas. Also, there are slight variations in the intensity of the refractive index peak as a result of increasing the gas pressure. It is found that the refractive index has the same peak at $360 \mathrm{~nm}$.

The variation of the refractive index $n$ in the region of very small values of the extinction coefficient $k$, under negligible damping are provided by the classic dispersion theory. Wemple and DiDomenico described the wavelength dependence of the refractive index, $n$, in the transparent region for various different solids by using the single-oscillator model of the form [51]:

$$
\left(n^{2}-1\right)^{-1}=\frac{E_{\text {dis }} E_{o}}{E_{o}^{2}-(h \vartheta)^{2}}
$$

where $h v$ represents the photon energy, $E_{o}$ is the energy of the oscillator and $E_{\text {dis }}$ is the dispersion energy which describes the strength of the electronic transitions. The calculated values of the dispersion parameters are obtained by plotting of $\left(n^{2}-1\right)^{-1}$ against $(h v)^{2}$ for the as-deposited $\mathrm{Sm}_{2} \mathrm{O}_{3}$ thin films as shown in Figure 7. The obtained dispersion parameters are recorded in Table 1. 


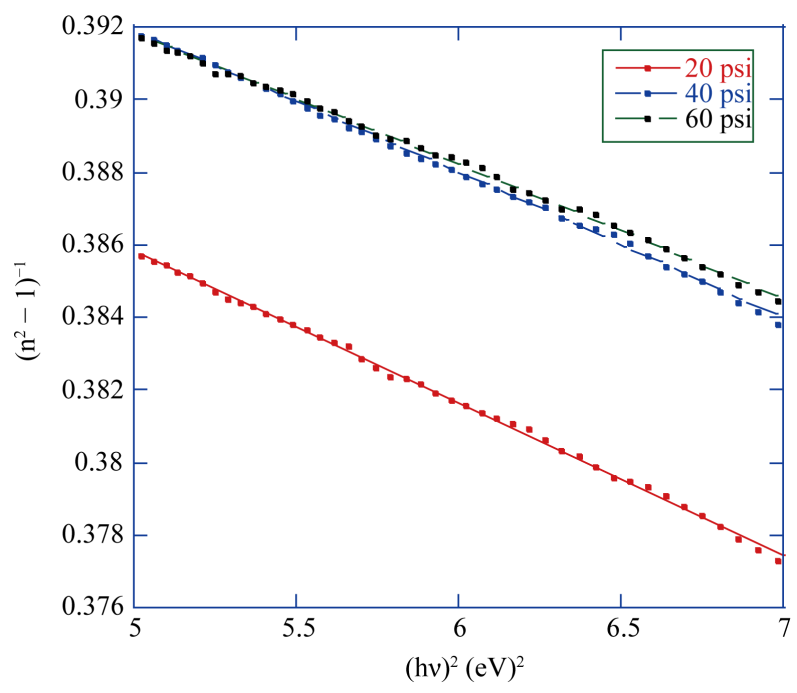

Figure 7. Plots of $\left(\mathrm{n}^{2}-1\right)^{-1}$ versus $(h v)$ for $\mathrm{Sm}_{2} \mathrm{O}_{3}$ thin films deposited under different pressure of the gas.

Table 1. Dispersion parameters of $\mathrm{Sm}_{2} \mathrm{O}_{3}$ thin films with respect to pressure of the gas.

\begin{tabular}{cccccc}
\hline Pressure & $\varepsilon_{\infty}$ & $\varepsilon_{L}$ & $\mathrm{~N} / \mathrm{m}^{*}\left(10^{45} \mathrm{~kg}^{-1} \cdot \mathrm{m}^{-3}\right)$ & $E_{o}(\mathrm{eV})$ & $E_{\text {dis }}(\mathrm{eV})$ \\
\hline $20 \mathrm{psi}$ & 3.46 & 3.71 & 48.4 & 9.83 & 24.15 \\
$40 \mathrm{psi}$ & 3.43 & 3.66 & 46.9 & 10.17 & 24.69 \\
$60 \mathrm{psi}$ & 3.44 & 3.65 & 46.4 & 10.58 & 25.79 \\
\hline
\end{tabular}

The dispersion theory provides the description of the variation of $n^{2}$ versus $\lambda^{2}$ to obtain the lattice dielectric constant, $\varepsilon_{L}$, free carrier concentration to the free carrier effective mass $\mathrm{N} / \mathrm{m}^{*}$ and permittivity of free space $\varepsilon_{0}$. Figure 8 shows the relation between $n^{2}$ and $\lambda^{2}$ for the as-deposited $\mathrm{Sm}_{2} \mathrm{O}_{3}$ thin films. It is observed that the dependence of $n^{2}$ on $\lambda^{2}$ is linear at longer wavelengths. Extrapolating these linear parts to zero wavelengths gives the value of $\varepsilon_{L}$ and from the slopes of these linear parts $\mathrm{N} / \mathrm{m}^{*}$. The calculated parameters are recorded in Table 1.

It is noticed from Table 1 that each of $\varepsilon_{\infty}, \varepsilon_{L}$ and $\mathrm{N} / \mathrm{m}^{*}$ seem to be deceased with increasing the pressure of the gas. Whereas both of $E_{o}$ and $E_{\text {dis }}$ increase with pressure of the gas. The disagreement between $\varepsilon_{L}$ and $\varepsilon_{\infty}$ may be due to free carriers' contribution [52].

The spectral distribution of the complex dielectric constant $\varepsilon$ describes the propagation, reflection and loss of light in multilayer structures, besides, it can be expressed by the following equation:

$$
\varepsilon=\varepsilon_{1}-i \varepsilon_{2}
$$

where $\varepsilon_{1}=n^{2}-k^{2}$ and $\varepsilon_{2}=2 n k$ are the real and imaginary part of the complex dielectric constant respectively. The spectral distribution of $\varepsilon_{1}$ and $\varepsilon_{2}$ for $\mathrm{Sm}_{2} \mathrm{O}_{3}$ thin films are shown in Figure 9 \& Figure 10. These figures show that the spectral distribution of $\varepsilon_{1}$ in the visible range of wavelength follows the same behaviour of the real part of the refractive index, whereas, the spectral distribution of $\varepsilon_{2}$ found to follow the behavior of $\alpha$ throw the same range of photon energy.

The real $\sigma_{1}$ and imaginary $\sigma_{2}$ components of optical conductivity are described as [53]:

$$
\sigma_{1}=\omega \varepsilon_{2} \varepsilon_{o} \sigma_{2}=\omega \varepsilon_{1} \varepsilon_{o}
$$

where $\omega$ is the angular frequency, $\varepsilon_{o}$ is the permittivity of free space. The spectra of real and imaginary parts of the optical conductivity are shown in Figure 11. It can be observed that the real part of the optical conductivity $\sigma_{1}$ increases by increasing energy. This suggests that the increase in optical conductivity is due to electrons excited by photon energy [53]. 


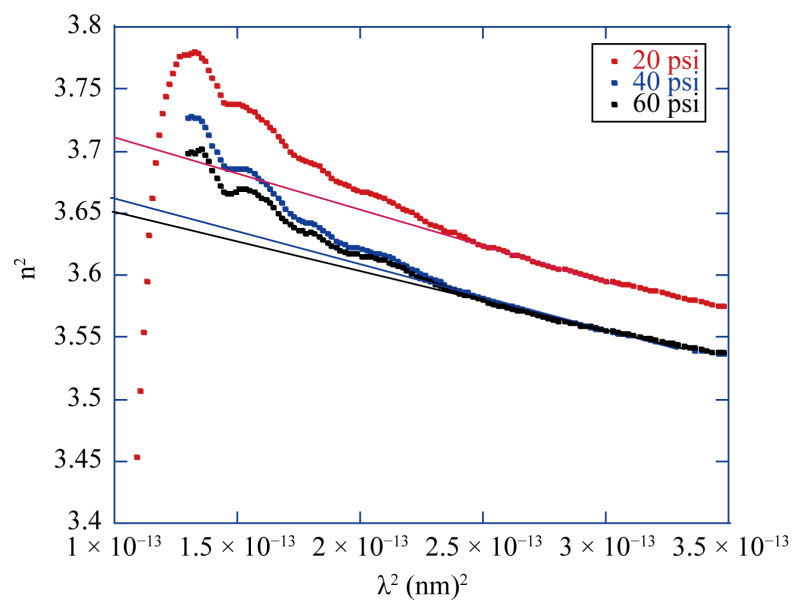

Figure 8. Plots of $n^{2}$ versus $\lambda^{2}$ for $\mathrm{Sm}_{2} \mathrm{O}_{3}$ thin films deposited under different pressure of the gas.

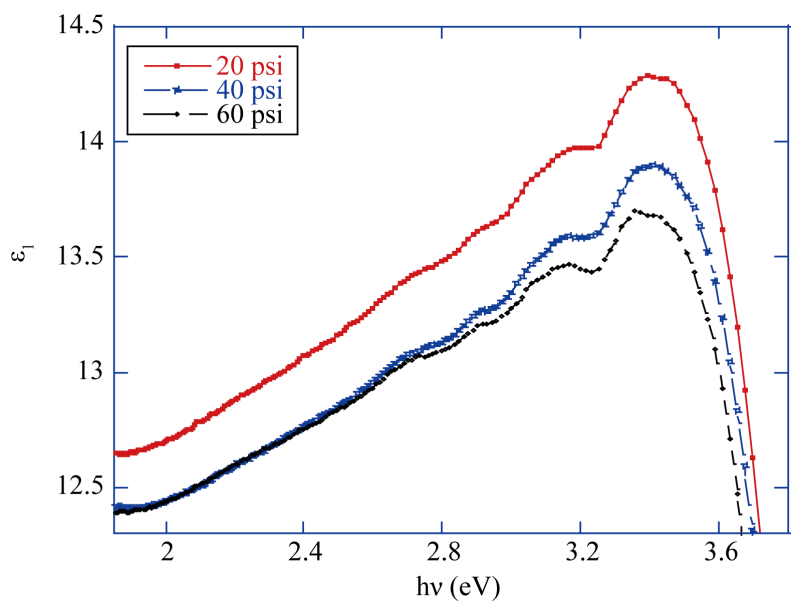

Figure 9. Plots of real part $\left(\varepsilon_{1}\right)$ of the dielectric constant versus $(h v)$ for $\mathrm{Sm}_{2} \mathrm{O}_{3}$ thin films prepared under different pressure of the gas.

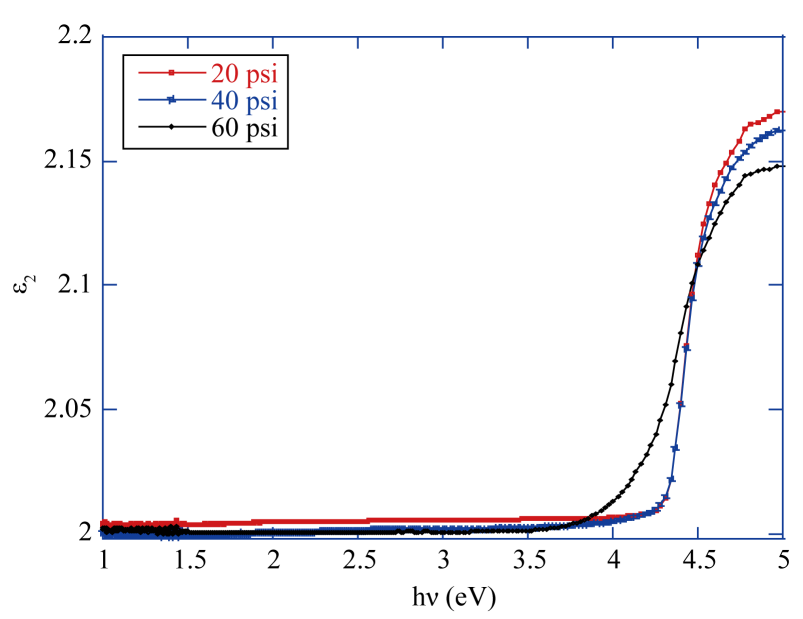

Figure 10. Plots of imaginary part of the dielectric constant $\left(\varepsilon_{2}\right)$ versus $(h v)$ for $\mathrm{Sm}_{2} \mathrm{O}_{3}$ thin films prepared under different pressure of the gas. 
The volume and surface loss functions (VELF and SELF) are proportional to the characteristics energy loss of fast electrons traveling the bulk and surface of the material, respectively. They related to the real and imaginary parts of the dielectric constant and can be calculated by using the relations [41]:

$$
\begin{aligned}
& \mathrm{VELF}=\frac{\varepsilon_{2}^{2}}{\varepsilon_{1}^{2}-\varepsilon_{2}^{2}} \\
& \mathrm{SELF}=\frac{\varepsilon_{2}^{2}}{\left(\varepsilon_{1}+1\right)^{2}+\varepsilon_{2}^{2}}
\end{aligned}
$$

Figure 12 shows the behavior of the VELF and FELF with photon energy revealing that both of them seem to be independent on photon energy in the range $2.5 \mathrm{eV}-3.6 \mathrm{eV}$. Also, it is clear that the maximum of SELF and VELF correspond to the absorption energy due to the interband transition that occurs at $4.13 \mathrm{eV}$ and $4.53 \mathrm{eV}$. Both the energy losses takes place when the fast single electrons traverses from valance band to conduction band in the film under test.

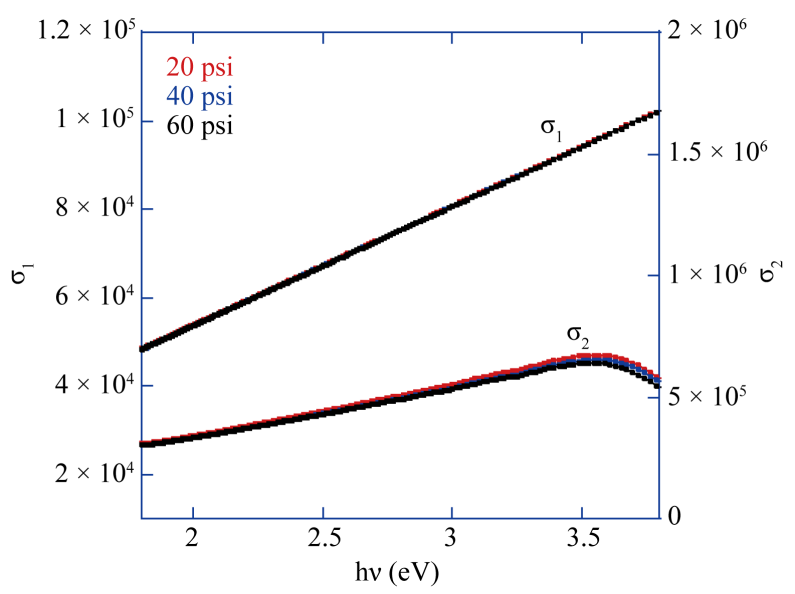

Figure 11. Plots of optical conductivity $\sigma$ versus $(h v)$ for $\mathrm{Sm}_{2} \mathrm{O}_{3}$ thin films deposited ubder different pressure of the gas.

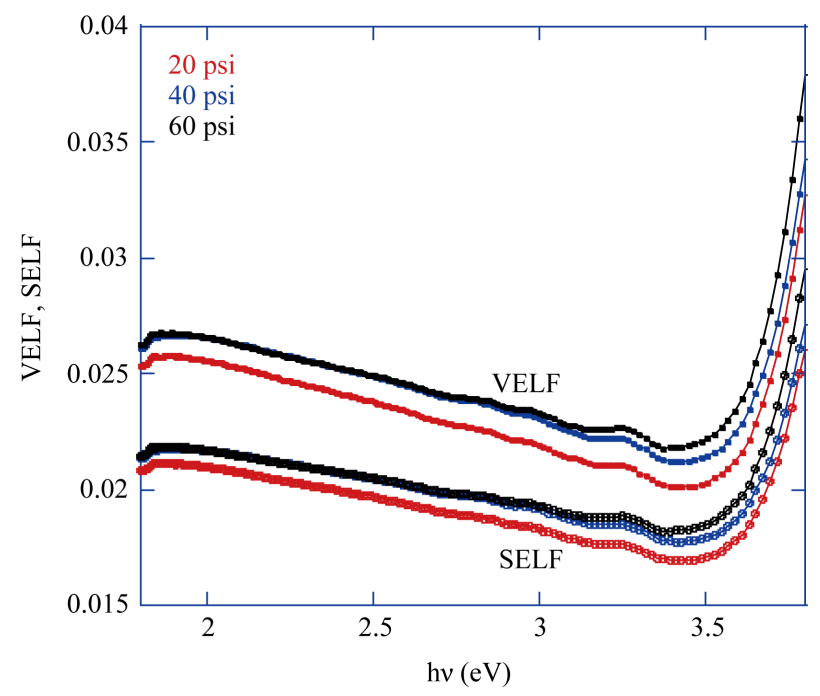

Figure 12. Plots of VELF and SELF versus incedent photon energy for $\mathrm{Sm}_{2} \mathrm{O}_{3}$ thin films deposited under different pressure of the gas. 


\section{Conclusion}

RF magnetron sputtering is used for preparing $\mathrm{Sm}_{2} \mathrm{O}_{3}$ thin films. Two peaks characterizing $\mathrm{Sm}_{2} \mathrm{O}_{3}$ are detected by X-ray diffraction patterns. The optical gap decreases with increasing argon pressure. Refractive index and optical conductivity decrease wit increasing the pressure of the gas. Dispersion and single oscillator energies increase with increasing the pressure of the gas. VELF and SELF found to decrease with the increase of the pressure of the gas.

\section{Acknowledgements}

The project was financially supported by King Saud University, Vice Deanship of research chairs.

\section{References}

[1] Wilk, G.D., Wallace, R.M. and Anthony, J.M. (2001) High-к Gate Dielectrics: Current Status and Materials Properties Considerations. Journal of Applied Physics, 89, 5243-5275. http://dx.doi.org/10.1063/1.1361065

[2] Wong, H. and Iwai, H. (2006) On the Scaling Issues and High- $\kappa$ Replacement of Ultrathin Gate Dielectrics for Nanoscale MOS Transistors. Microelectronic Engineering, 83, 1867-904. http://dx.doi.org/10.1016/j.mee.2006.01.271

[3] Wong, Y.H. and Cheong, K.Y. (2010) $\mathrm{ZrO}_{2}$ Thin Films on Si Substrate. Journal of Materials Science: Materials in Electronics, 21, 980-993. http://dx.doi.org/10.1007/s10854-010-0144-5

[4] Jagadeesh Chandra, S.V., Choi, C.-J., Uthanna, S. and Mohan Rao, G. (2010) Structural and Electrical Properties of Radio Frequency Magnetron Sputtered Tantalum Oxide Films: Influence of Post-Deposition Annealing. Materials Science in Semiconductor Processing, 13, 245-251. http://dx.doi.org/10.1016/j.mssp.2010.08.002

[5] Buchanan, D.A. and Lo, S.H. (1997) Reliability and Integration of Ultra-Thin Gate Dielectrics for Advanced CMOS. Microelectronic Engineering, 36, 13. http://dx.doi.org/10.1016/S0167-9317(97)00007-5

[6] Heiser, G. and Schenk, A. (1997) Modeling and Simulation of Tunneling through Ultra-Thin Gate Dielectrics. Journal of Applied Physics, 81, 7900. http://dx.doi.org/10.1063/1.365364

[7] Alers, G.B., Werder, D.J., Chabal, Y., Lu, H.C., Gusev, E.P., Garfunkel, E., Gustafsson, T. and Urdahl, R.S. (1998) Intermixing at the Tantalum Oxide/Silicon Interface in Gate Dielectric Structures. Applied Physics Letters, 73, 1517. http://dx.doi.org/10.1063/1.122191

[8] Leskel, M. and Ritala, M. (2003) Rare-Earth Oxide Thin Films as Gate Oxides in MOSFET Transistors. Journal of Solid State Chemistry, 171, 170-174. http://dx.doi.org/10.1016/S0022-4596(02)00204-9

[9] Kao, C.-H., Chen, H., Chiu, J.S., Chen, K.S. and Pan, Y.T. (2010) Physical and Electrical Characteristics of the High-k $\mathrm{Ta}_{2} \mathrm{O}_{5}$ (Tantalum Pentoxide) Dielectric Deposited on the Polycrystalline Silicon. Applied Physics Letters, 96, 11129013. http://dx.doi.org/10.1063/1.3334725

[10] Chakraborty, S., Bera, M.K. Bhattacharya, S. and Maiti, C.K. (2005) Current Conduction Mechanism in TiO ${ }_{2}$ Gate Dielectrics. Microelectronic Engineering, 81, 188-193. http://dx.doi.org/10.1016/j.mee.2005.03.005

[11] Chen, C.-W., Chien, C.-H., Perng, T.-H., Yang, M.-J., Liang, J.-S., Lehnen, P., Tsui, B.-Y. and Chang, C.-Y. (2005) Electrical Characteristics of Thin $\mathrm{HfO}_{2}$ Gate Dielectrics Prepared Using Different Pre-Deposition Surface Treatments. Japanese Journal of Applied Physics, 44, 87-93. http://dx.doi.org/10.1143/JJAP.44.87

[12] Mbarek, I.B., Chaabouni, F., Selmi, M., Abaab, M. and Rezig, B. (2010) Effect of the Substrate Temperature on the Properties of the RF Sputtered $\mathrm{TiO}_{2}$ Thin Films. Physica Status Solidi (c), 7, 2311-2315. http://dx.doi.org/10.1002/pssc.200983739

[13] Srivastava, A., Nahar, R. and Sarkar, C. (2010) Study of the Effect of Thermal Annealing on High $k$ Hafnium Oxide Thin Film Structure and Electrical Properties of MOS and MIM Devices. Journal of Materials Science: Materials in Electronics, 22, 882-889. http://dx.doi.org/10.1007/s10854-010-0230-8

[14] Khaleeq-ur-Rahman, M., Bhatti, K.A., Rafique, M.S., Anjum, S., Latif, A. and Anjum, M. (2010) Morphological and Structural Analysis of Nano-Structured Gold Thin Film on Silicon by Pulsed Laser Deposition Technique. Vacuum, 85, 353-357. http://dx.doi.org/10.1016/j.vacuum.2010.05.002

[15] Sang, J., Ha, J.S., Park, N.K., Kang, D.K. and Kim, B.-H. (2006) 5 nm Thick Lanthanum Oxide Thin Films Grown on $\mathrm{Si}(100)$ by Atomic Layer Deposition: The Effect of Post-Annealing on the Electrical Properties. Thin Solid Films, 513, 253-257. http://dx.doi.org/10.1016/j.tsf.2006.01.008

[16] Lo Nigro, R., Toro, R.G., Malandrino, G., Fragal, I.L., Raineri, V. and Fiorenza, P. (2006) Praseodymium Based High- $k$ Dielectrics Grown on Si and SiC Substrates. Materials Science in Semiconductor Processing, 9, 1073-1078. http://dx.doi.org/10.1016/j.mssp.2006.10.026 
[17] Dakhel, A.A. (2005) Characterisation of Oxidised Gadolinium Film Deposited on Si(100) Substrate. Journal of Alloys and Compounds, 388, 177-185. http://dx.doi.org/10.1016/j.jallcom.2004.07.019

[18] Dakhel, A.A. (2004) Electrical Conduction Processes in Neodymium Oxide Thin Films Prepared on Si(100) Substrates. Journal of Alloys and Compounds, 376, 38-42. http://dx.doi.org/10.1016/j.jallcom.2004.01.009

[19] Pan, T.-M. and Huang, W.-S. (2009) Physical and Electrical Characteristics of a High- $k \mathrm{Yb}_{2} \mathrm{O}_{3}$ Gate Dielectric. Applied Surface Science, 255, 4979-4982. http://dx.doi.org/10.1016/j.apsusc.2008.12.048

[20] Leskela, M., Kukli, K. and Ritala, M. (2006) Rare-Earth Oxide Thin Films for Gate Dielectrics in Microelectronics. Journal of Alloys and Compounds, 418, 27-34. http://dx.doi.org/10.1016/j.jallcom.2005.10.061

[21] Chiu, F.-C. (2010) Thickness and Temperature Dependence of Dielectric Reliability Characteristics in Cerium Dioxide Thin Film. IEEE Transactions on Electron Devices, 57, 2719-2725.

[22] Kim, W.-H., Maeng, W.J., Moon, K.-J., Myoung, J.-M. and Kim, H. (2010) Growth Characteristics and Electrical Properties of $\mathrm{La}_{2} \mathrm{O}_{3}$ Gate Oxides Grown by Thermal and Plasma-Enhanced Atomic Layer Deposition. Thin Solid Films, 519, 362-366. http://dx.doi.org/10.1016/j.tsf.2010.07.108

[23] Pan, T.-M. and Huang, C.-C. (2010) Effects of Oxygen Content and Postdeposition Annealing on the Physical and Electrical Properties of Thin $\mathrm{Sm}_{2} \mathrm{O}_{3}$ Gate Dielectrics. Applied Surface Science, 256, 7186-7193. http://dx.doi.org/10.1016/j.apsusc.2010.05.048

[24] Pan, T.-M. and Yen, L.-C. (2010) Influence of Postdeposition Annealing on Structural Properties and Electrical Characteristics of Thin $\mathrm{Tm}_{2} \mathrm{O}_{3}$ and $\mathrm{Tm}_{2} \mathrm{Ti}_{2} \mathrm{O}_{7}$ Dielectrics. Applied Surface Science, 256, 2786-2791. http://dx.doi.org/10.1016/j.apsusc.2009.11.029

[25] Yang, C., Fan, H., Qiu, S., Xi, Y. and Fu, Y. (2009) Microstructure and Dielectric Properties of $\mathrm{La}_{2} \mathrm{O}_{3}$ Films Prepared by Ion Beam Assistant Electron-Beam Evaporation. Journal of Non-Crystalline Solids, 355, 33-37. http://dx.doi.org/10.1016/j.jnoncrysol.2008.09.029

[26] Dakhel, A.A. (2004) Dielectric and Optical Properties of Samarium Oxide Thin Films. Journal of Alloys and Compounds, 365, 233-239. http://dx.doi.org/10.1016/S0925-8388(03)00615-7

[27] Paivasaari, J., Putkonen, M. and Niinist, L.A. (2005) A Comparative Study on Lanthanide Oxide Thin Films Grown by Atomic Layer Deposition. Thin Solid Films, 472, 275-281. http://dx.doi.org/10.1016/j.tsf.2004.06.160

[28] Yang, D., Xue, L.I. and Devine, R.A.B. (2003) Charge Trapping in and Electrical Properties of Pulsed Laser Deposited $\mathrm{Sm}_{2} \mathrm{O}_{3}$ Films. Journal of Applied Physics, 93, 9389. http://dx.doi.org/10.1063/1.1569660

[29] Shalini, K. and Shivashankar, S. (2005) Oriented Growth of Thin Films of Samarium Oxide by MOCVD. Bulletin of Materials Science, 28, 49-54. http://dx.doi.org/10.1007/BF02711172

[30] Pan, T.-M., Huang, C.-C., You, S.-X. and Yeh, C.-C. (2008) Effect of Annealing on the Structural and Electrical Properties of High- $k \mathrm{Sm}_{2} \mathrm{O}_{3}$ Dielectrics. Electrochemical and Solid-State Letters, 11, G62-G65. http://dx.doi.org/10.1149/1.2990226

[31] Chin, W.C., Cheong, K.Y. and Hassan, Z. (2010) $\mathrm{Sm}_{2} \mathrm{O}_{3}$ Gate Dielectric on Si Substrate. Materials Science in Semiconductor Processing, 13, 303-314. http://dx.doi.org/10.1016/j.mssp.2011.02.001

[32] Kaya, S., Yilmaz, E., Karacali, H., Cetinkaya, A.O. and Aktag, A. (2015) Samarium Oxide Thin Films Deposited by Reactive Sputtering: Effects of Sputtering Power and Substrate Temperature on Microstructure, Morphology and Electrical Properties. Materials Science in Semiconductor Processing, 33, 42-48. http://dx.doi.org/10.1016/j.mssp.2015.01.035

[33] AmaliRoselin, A., Anandhan, N., Ravi, G., Mummoorthi, M. and Marimuthu, T. (2014) Growth and Characterization of $\mathrm{Sm}_{2} \mathrm{O}_{3}$ Thin Films by Spin Coating Technique. International Journal of ChemTech Research, 6, 5315-5320.

[34] Kang, J.-G., Min, B.-K. and Sohn, Y. (2015) Synthesis and Characterization of $\mathrm{Sm}(\mathrm{OH})_{3}$ and $\mathrm{Sm}_{2} \mathrm{O}_{3}$ Nanoroll Sticks. Journal of Materials Science, 50, 1958-1964. http://dx.doi.org/10.1007/s10853-014-8760-8

[35] Tolansky, S., Ed. (1978) Multiple-Beam Interferometry Surface and Films. Oxford University Press, London, 76.

[36] El-Nahass, M.M. (1992) Optical Properties of Tin Diselenide Films. Journal of Materials Science, 27, 6597-6604. http://dx.doi.org/10.1007/BF01165942

[37] Di Giulio, M., Micocci, G., Rella, R., Siciliano, P. and Tepore, A. (1993) Optical Absorption of Tellurium Suboxide Thin Films. Physica Status Solidi (a), 136, K101-K104. http://dx.doi.org/10.1002/pssa.2211360236

[38] El-Nahass, M.M., El-Deeb, A.F., Metwally, H.S. and Hassanien, A.M. (2010) Structural and Optical Properties of Iron (III) Chloride Tetraphenylporphyrin Thin Films. The European Physical Journal Applied Physics, 52, 10403. http://dx.doi.org/10.1051/epjap/2010134

[39] El-Nahass, M.M., El-Deeb, A.F., Metwally, H.S., El-Sayed, H.E.A. and Hassanien, A.M. (2010) Influence of X-Ray Irradiation on the Optical Properties of Iron (III) Chloride Tetraphenylporphyrin Thin Films. Solid State Sciences, 12, 552-557. http://dx.doi.org/10.1016/j.solidstatesciences.2010.01.004 
[40] El-Nahhas, M.M., Farid, A.M., Attia, A.A. and Ali, H.A.M. (2006) Structural Properties and UV to NIR Absorption Spectra of Metal-Free Phthalocyanine $\left(\mathrm{H}_{2} \mathrm{Pc}\right)$ Thin Films. Fizika A, 15, 147-164.

[41] El-Nahass, M.M., El-Gohary, Z. and Soliman, H.S. (2003) Structural and Optical Studies of Thermally Evaporated CoPc Thin Films. Optics \& Laser Technology, 35, 523-531. http://dx.doi.org/10.1016/S0030-3992(03)00068-9

[42] Pal, U., Samanta, D., Ghori, S. and Chaudhuri, A.K. (1993) Optical Constants of Vacuum-Evaporated Polycrystalline Cadmium Selenide Thin Films. Journal of Applied Physics, 74, 6368. http://dx.doi.org/10.1063/1.355161

[43] Constantinescu, C., Ion, V., Galca, A.C. and Dinescu, M. (2012) Morphological, Optical and Electrical Properties of Samarium Oxide Thin Films. Thin Solid Films, 520, 6393-6397. http://dx.doi.org/10.1016/j.tsf.2012.06.049

[44] Kumar, B., Gong, H. and Akkipeddi, R. (2005) A Study of Conduction in the Transition Zone between Homologous and $\mathrm{ZnO}$-Rich Regions in the $\mathrm{In}_{2} \mathrm{O}_{3}-\mathrm{ZnO}$ System. Journal of Applied Physics, 97, Article ID: 063706. http://dx.doi.org/10.1063/1.1862311

[45] Alhuthali, A., El-Nahass, M.M., Atta, A.A., El-Raheem, M.M.A., Elsabawy, K.M. and Hassanien, A.M. (2015) Study of Topological Morphology and Optical Properties of $\mathrm{SnO}_{2}$ Thin Films Deposited by RF Sputtering Technique. Journal of Luminescence, 158, 165-171. http://dx.doi.org/10.1016/j.jlumin.2014.09.044

[46] Mott, N.F. and Davis, E.A. (1979) Electronic Process in Non-Crystalline Materials. Clarendon Press, Oxford.

[47] Arshak, K. and Korostynska, O. (2006) Response of Metal Oxide Thin Film Structures to Radiation. Materials Science and Engineering: B, 133, 1-3. http://dx.doi.org/10.1016/j.mseb.2006.06.012

[48] Rakhshani, A.E. (2000) Study of Urbach Tail, Bandgap Energy and Grain-Boundary Characteristics in CdS by Modulated Photocurrent Spectroscopy. Journal of Physics: Condensed Matter, 12, 4391-4400.

[49] Urbach, F. (1953) The Long-Wavelength Edge of Photographic Sensitivity and of the Electronic Absorption of Solids. Physical Review, 92, 1324. http://dx.doi.org/10.1103/PhysRev.92.1324

[50] Turku, B.I., Kapustianyk, V.B., Rudy, V.P., Lubochkova, G.A. and Simkiv, B.A. (2006) Investigation of the Intrinsic Absorption Edge in Nanostructured Polycrystalline Zinc Oxide Thin Films. Journal of Applied Spectroscopy, 73, $222-$ 226. http://dx.doi.org/10.1007/s10812-006-0062-8

[51] Wemple, S.H. (1973) Refractive-Index Behavior of Amorphous Semiconductors and Glasses. Physical Review B, 7, 3767. http://dx.doi.org/10.1103/PhysRevB.7.3767

[52] Konstantinov, I., Babeva, T. and Kitova, S. (1998) Analysis of Errors in Thin-Film Optical Parameters Derived from Spectrophotometric Measurements at Normal Light Incidence. Applied Optics, 37, 4260-4267. http://dx.doi.org/10.1364/AO.37.004260

[53] Caglar, Y., Ilican, S. and Caglar, M. (2007) Single-Oscillator Model and Determination of Optical Constants of Spray Pyrolyzed Amorphous $\mathrm{SnO}_{2}$ Thin Films. The European Physical Journal B, 58, 251-256. http://dx.doi.org/10.1140/epjb/e2007-00227-y 